\title{
Dopamine D2 Receptor-Mediated Inhibition of Dopaminergic Neurons in Mice Lacking D2L Receptors
}

Diego Centonze, M.D., Alessandro Usiello, Ph.D., Paolo Gubellini, Ph.D., Antonio Pisani, M.D., Emiliana Borrelli, Ph.D., Giorgio Bernardi, M.D., and Paolo Calabresi, M.D.

Two isoforms of the dopamine (DA) D2 receptor are generated from the same gene by alternative splicing, D2L and D2S. To identify which isoform is involved in the autoregulation of midbrain DA neuron activity, intracellular electrophysiological recordings were performed from substantia nigra and ventral tegmental area neurons of mice lacking either D2L(D2L-/-) or both D2L and D2S receptors (D2-/-). In midbrain DA neurons from wildtype mice, DA and quinpirole, a DA D2-like receptor agonist, produced a significant somatic membrane hyperpolarization, which led to a reversible inhibition of firing activity. Interestingly, this effect was fully abolished in D2-/- neurons but still present in D2L-/-DA neurons. These data clearly show that $D 2 S$ receptors are the main somatodendritic autoreceptors of central DA neurons. Thus, pharmacological compounds able to interfere selectively with presynaptic D2S receptors might constitute effective therapeutic strategies in neuropsychiatric disorders, by causing negligible side-effects.

[Neuropsychopharmacology 27:723-726, 2002] (C) 2002 American College of Neuropsychopharmacology. Published by Elsevier Science Inc.
KEY WORDS: D2 receptor isoforms; Electrophysiology; Parkinson's disease; Schizophrenia; Substantia nigra; Ventral tegmental area

Most parts of the central nervous system contain dopamine (DA), a monoamine neurotransmitter released by axon terminals of midbrain neurons of the substantia nigra (SN) and ventral tegmental area (VTA). Since the discovery that DA exerts its physiolog-

From the Clinica Neurologica, Dipartimento di Neuroscienze, Università "Tor Vergata" and Fondazione Santa Lucia, IRCCS, Rome, Italy (DC, PG, AP, GB, PC), and Institut de Génétique et de Biologie Moléculaire et Cellulaire, CNRS-INSERM-ULP, CU de Strasbourg, France (AU, EB).

Address correspondence to: Dr. Paolo Calabresi, Clinica Neurologica, Dipartimento di Neuroscienze, Università di Tor Vergata, Via di Tor Vergata 135, Rome 00133, Italy. Tel. 0039-06-7259-6010; Fax: 0039-06-7259-6006; E-mail: calabre@uniroma2.it.

Received February 26, 2002; revised March 22, 2002; accepted March 28, 2002.

Online publication: 5/3/02 at www.acnp.org/citations/Npp 050302302 ical action by binding to multiple receptors (Kebabian and Calne 1979), five distinct G-protein-coupled DA receptors have been identified. The D1 and D5 receptors form the D1-like subfamily, while D2, D3 and D4 receptors constitute the D2-like subfamily. Receptors of the D1-like subtype are positive regulators of cyclic adenosine monophosphate (AMP) levels, while the inhibition of cyclic AMP synthesis is a general property of D2-like receptors (Stoof and Kebabian 1981). Although the anatomical distributions of DA receptors tend to overlap in the brain, their quantitative ratios differ significantly in several anatomical areas, supporting the concept that specific subtypes of DA receptors serve specific physiological roles. A crucial role of the D2-like receptors is the regulation of DA release by acting as autoreceptors on the somatodendritic region of midbrain DAergic neurons. In rodents, in fact, administration of low doses of the D2-like selective agonist quinpirole induces suppression of motor activity, a pharmacological effect generally ascribed to the reduction of DA release in the 
striatum (Starke et al. 1989; Usiello et al. 2000). Although midbrain DA neurons express functional D2 and D3 receptors (Tepper et al. 1997; Diaz et al. 2000), physiological studies have emphasized the involvement of D2 receptors as somatodendritic, impulse-regulating autoreceptors on DA neurons. Indeed, DA neurons from mice lacking D2 receptors but still expressing D3 receptors are insensitive to DA and quinpirole in electrophysiological recordings in vitro (Mercuri et al. 1997), whereas DA neurons in mice lacking D3 receptors exhibit normal sensitivity to quinpirole (Koeltzow et al. 1998).

Interestingly, two isoforms of the D2 receptor are generated from the same gene by alternative splicing, D2L and D2S. D2L and D2S receptors display differential affinities for inhibitory G-proteins (Guiramand et al. 1995), suggesting that their transduction pathways and physiological roles might not be equivalent. This hypothesis was also supported by evidence that the expression ratio of D2L versus D2S receptors is region specific throughout the brain (Montmayeur et al. 1991). More recently, genetic disruption of D2L receptors (Usiello et al. 2000) has confirmed these hypotheses. Indeed, in D2L lacking mice some D2L-receptor-mediated behavioral deficits are not compensated by the concomitant D2S receptor overexpression (Usiello et al. 2000; Wang et al. 2000).

The unavailability of pharmacological agents able to discriminate between D2L and D2S receptors makes essential the use of mutant mice to address the role of the two isoforms of D2 receptors in terms of single neuron physiology. In the present study, we used mice in which the expression of D2L receptors was selectively ablated (D2L-/-) to investigate the involvement of this isoform of the D2 receptor in the autoregulation of midbrain DA neurons. To this end, in vitro electrophysiological recordings were performed from the somatic region of SN and VTA neurons of these mutants. The effects of DA and quinpirole in D2L-/- were compared with those elicited in wild-type (WT) mice as well as in mice lacking both the D2L and D2S receptors $(\mathrm{D} 2-/-)$. The generation of the D2-/- and D2L-/mice used in this study has been reported previously (Baik et al. 1995; Usiello et al. 2000).

Conventional intracellular sharp microelectrode recordings were performed in horizontal midbrain slices (200-300 $\mu \mathrm{m}$ thickness), as previously described for both rat and mouse preparations (Mercuri et al. 1995, 1997). The recording electrodes were filled with $2 \mathrm{M} \mathrm{KCl}$ and had a tip resistance of 30-60 M $\Omega$. Under these experimental conditions, the intrinsic membrane properties of $\mathrm{SN}$ and VTA DA neurons did not significantly differ in WT, D2L - / - and D2-/ - mice, and closely resembled those reported previously for mouse DA neurons recorded in vitro (Grace and Onn 1989; Lacey et al. 1989; Mercuri et al. 1997). DA neurons of WT mice fired action potentials spontaneously at a rate of $2.2 \pm 0.3 \mathrm{~Hz}(\mathrm{n}=15)$, while in $\mathrm{D} 2 \mathrm{~L}-/-(\mathrm{n}=16)$ and in $\mathrm{D} 2-/-(\mathrm{n}=16)$ DA neurons the mean frequency of spontaneous firing activity was $2.7 \pm 0.4 \mathrm{~Hz}(p>.05)$ and $2.1 \pm 0.2 \mathrm{~Hz}(p>.05)$, respectively. The mean peak input resistance, measured within $200 \mathrm{~ms}$ of a hyperpolarizing pulse, was $167 \pm 15 \mathrm{M} \Omega$ in

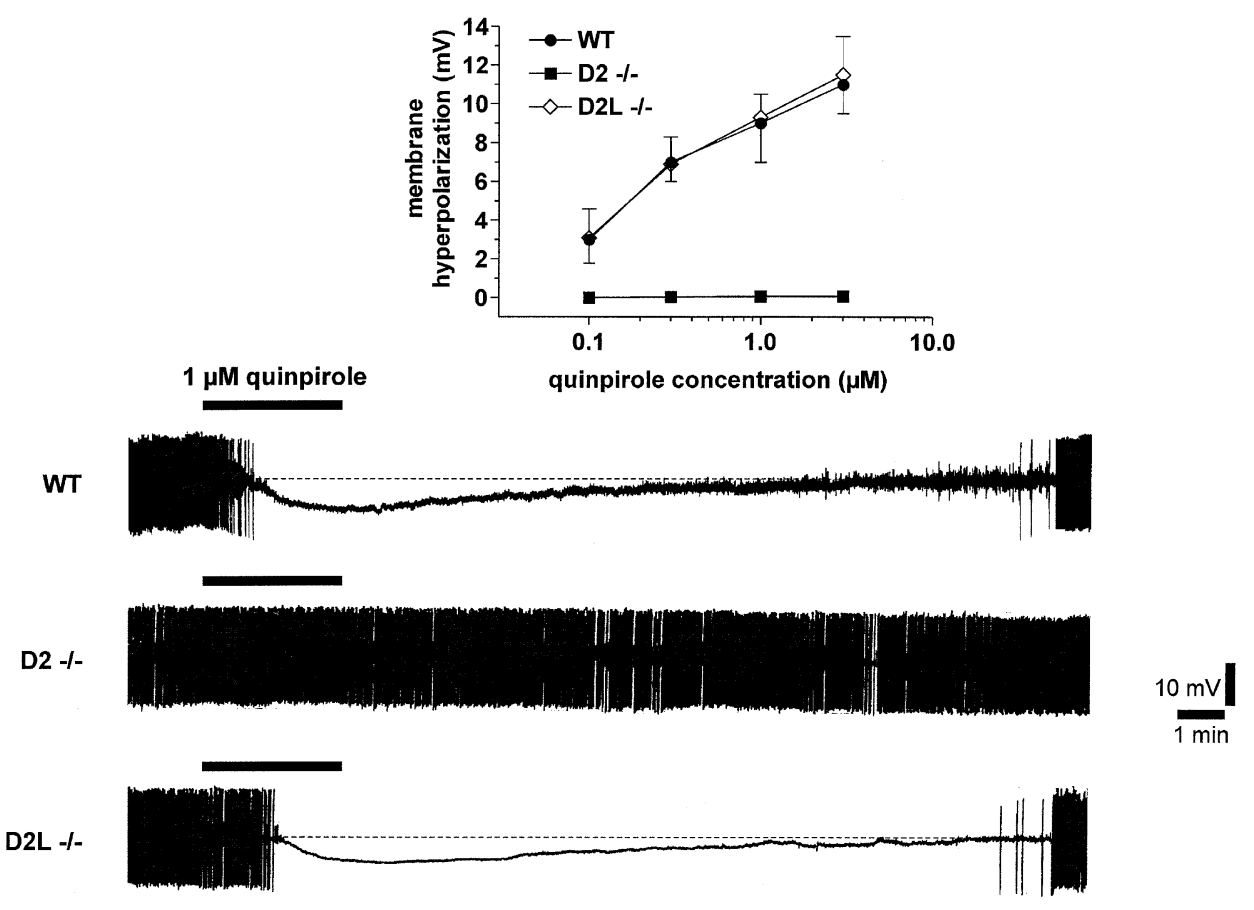

Figure 1. Effects of the DA D2 receptor agonist quinpirole on midbrain DA neurons of WT, D2L-/- and D2-/- mice. The graph shows that quinpirole induces a dose-dependent membrane hyperpolarization both in WT and D2L-/- DA neurons, while it is ineffective in DA cells of D2-/- mice. Each data point was obtained from at least four different experiments. The electrophysiological traces show that the application of $1 \mu \mathrm{M}$ quinpirole for $3 \mathrm{~min}$ induces a reversible hyperpolarization and inhibits spontaneous firing in both WT and D2L-/- but not in D2- / - neurons. Traces are from single intracellular electrophysiological experiments. 
WT DA neurons, $168 \pm 16 \mathrm{M} \Omega$ in $\mathrm{D} 2 \mathrm{~L}-/-(p>.05)$ and $166 \pm 14 \mathrm{M} \Omega$ in D2- / - DA neurons $(p>.05)$.

As previously reported (Mercuri et al. 1997), application of $30 \mu \mathrm{M} \mathrm{DA}$ (3-5 min; $\mathrm{n}=4$; not shown) or of $0.1-30$ $\mu \mathrm{M}$ quinpirole $(3-5 \mathrm{~min} ; \mathrm{n}=10)$ caused in DA neurons of WT mice a dose-dependent membrane hyperpolarization, which led to a reversible inhibition of firing activity. This effect was likely mediated by the stimulation of somatodendritic D2S receptors, as it was fully abolished in D2-/ - DA neurons ( $\mathrm{n}=3$ for DA and $\mathrm{n}=9$ for quinpirole), and was unaltered in D2L-/ - DA neurons ( $\mathrm{n}=$ 6 for DA and $\mathrm{n}=12$ for quinpirole) (Figure 1). The involvement of D2 receptors, in the DA- and quinpiroleeffects evoked in D2L-/ - neurons, was also confirmed by the ability of the D2-like receptor antagonist L-sulpiride $(3-10 \mu \mathrm{M})$ to fully prevent the action of both $30 \mu \mathrm{M}$ DA $(\mathrm{n}=7 ; p>.05)$ and $1 \mu \mathrm{M}$ quinpirole $(\mathrm{n}=6 ; p>.05)$ on these mutant mice (not shown).

The identification of the precise autoreceptor subtype involved in the regulation of the physiological activity of midbrain DA neurons is a crucial issue, mainly because changes in regulatory mechanisms of DA release may be involved in neuropsychiatric disorders in which DA neuronal systems have been implicated (Jaber et al. 1996). Since the early 1970s, in fact, it has been well known that DA D2-like receptors exert this autoregulatory function, and both antipsychotic and antiparkinsonian drugs exert their therapeutic action by binding to this class of receptors (Carlsson 2001). The clinical use of both antipsychotic and antiparkinsonian agents, however, is associated with the development of a series of motor and cognitive complications, which depend, at least in part, on the non-selective nature of their action, with concomitant modulation of both preand postsynaptic DA D2-like receptors. In this light, it is conceivable that pharmacological compounds able to interfere selectively with presynaptic DA receptors might constitute effective therapeutic strategies in these disorders, associated with less important side-effects.

In the present study, we confirmed that DA D2 receptors are the somatodendritic autoreceptors of both SN and VTA DA neurons (Mercuri et al. 1997) and provided direct evidence that $\mathrm{D} 2 \mathrm{~L}$ receptors do not play a major role in this presynaptic action, thereby implying $\mathrm{D} 2 \mathrm{~S}$ receptors as the main impulse-regulating DA autoreceptors. The development of selective D2S receptor antagonists and/or the generation of selective D2S receptor lacking mice, however, are critically important to further strengthen this conclusion.

\section{ACKNOWLEDGMENTS}

We thank Mr. Massimo Tolu for technical support. This work has been supported by the following grants: CNR and Ministero della Sanità (Progetto Finalizzato Schizofrenia) grants to P.C. and INSERM, CNRS, HUS, MILDT and ARC grants to E.B.

\section{REFERENCES}

Baik J-H, Picetti R, Saiardi A, Thiriet G, Dierich A, Depaulis A, Le Meur M, Borrelli E (1995): Parkinsonian-like locomotor impairment in mice lacking dopamine D2 receptors. Nature 377:424-428

Carlsson A (2001): A paradigm shift in brain research. Science 294:1021-1024

Diaz J, Pilon C, Le Foll B, Gros C, Triller A, Schwartz JC, Sokoloff P (2000): Dopamine D3 receptors expressed by all mesencephalic dopamine neurons. J Neurosci 20:8677-8684

Kebabian JW, Calne DB (1979): Multiple receptors for dopamine. Nature 277:93-96

Koeltzow TE, Xu M, Cooper DC, Hu XT, Tonegawa S, Wolf ME, White FJ (1998): Alterations in dopamine release but not dopamine autoreceptor function in dopamine D3 receptor mutant mice. J Neurosci 18:2231-2238

Grace AA, Onn SP (1989): Morphology and electrophysiological properties of immunocytochemically identified rat dopamine renrons recorded in vitro. J Neurosci 9:3463-3481

Guiramand J, Montmayeur JP, Ceraline J, Bhatia M, Borrelli E (1995): Alternative splicing of the dopamine D2 receptor directs specificity of coupling to G-proteins. J Biol Chem 270:7354-7358

Jaber M, Robinson SW, Missale C, Caron MG (1996): Dopamine receptors and brain function. Neuropharmacology 35:1503-1519

Lacey MG, Mercuri NB, North RA (1989): Two cell types in rat substantia nigra zona compacta distinguished by membrane properties and the action of dopamine and opioids. J Neurosci 9:1233-1241

Montmayeur JP, Bausero P, Amlaiky N, Maroteaux L, Hen R, Borrelli E (1991): Differential expression of the mouse D2 Dopamine receptor isoforms. FEBS Lett 278:239-243

Mercuri NB, Bonci A, Calabresi P, Stratta F, Bernardi G (1995): Properties of the hyperpolarization-activated cation current Ih in rat midbrain dopaminergic neurons. Eur J Neurosci 7:462-469

Mercuri NB, Saiardi A, Bonci A, Picetti R, Calabresi P, Bernardi G, Borrelli E (1997): Loss of autoreceptor function in dopaminergic neurons from dopamine D2 receptor deficient mice. Neuroscience 79:323-327

Starke K, Gothert M, Kilbinger H (1989): Modulation of neurotransmitter release by presynaptic autoreceptors. Physiol Rev 69:864-989

Stoof JC, Kebabian JW (1981): Opposing roles for D-1 and D2 dopamine receptors in efflux of cyclic AMP from rat neostriatum. Nature 294:366-368

Tepper JM, Sun BC, Martin LP, Creese I (1997): Functional 
roles of dopamine D2 and D3 autoreceptors on nigrostriatal neurons analyzed by antisense knockdown in vivo. J Neurosci 17:2519-2530

Usiello A, Baik J-H, Rougé-Pont F, Picetti R, Dierich A, LeMeur M, Piazza PV, Borrelli E (2000): Distinct func- tions of the two isoforms of dopamine D2 receptors. Nature 408:199-203

Wang Y, Xu R, Sasaoka T, Tonegawa S, Kung M-P, Sankoorikal E-B (2000): Dopamine D2 long receptor-deficient mice display alterations in striatum-dependent functions. J Neurosci 20:8305-8314 